\title{
A Noonan-like short stature syndrome with sparse hair
}

\author{
M BARAITSER AND M A PATTON \\ From the Clinical Genetics Unit, The Hospital for Sick Children, Great Ormond Street, London WC1N3JH.
}

SUMMARY Noonan's syndrome is a clinically recognisable short stature syndrome with autosomal dominant inheritance. The diagnosis can be difficult as the phenotypic expression is very variable. There has been an attempt ${ }^{1}$ to divide this syndrome into type $I$ (in which the facial features, especially ptosis, antimongoloid eye slant, and hypertelorism are prominent) and type II (where cardiological abnormalities are more to the fore), but this has not yet been confirmed by other studies.

We report four children, all of short stature, none with the characteristic facial features of Noonan's syndrome, but with a low hairline, shield shaped chest, and cardiac lesions, in whom poor hair growth has been an outstanding dysmorphic feature. We suggest that this syndrome is distinct from Noonan's syndrome.

\section{Case reports}

CASE 1 (FIG 1)

The only child of non-consanguineous parents was

Received for publication 31 December 1984

Revised version accepted for publication 7 March 1985 born after a pregnancy complicated by polyhydramnios. Her birth weight was $2.7 \mathrm{~kg}$ at term. She was a slow feeder for three months and vomited intermittently until 14 months of age. On examination at 4 years her height was $98 \mathrm{~cm}$ (below the 3rd centile) and she had low set, posteriorly rotated ears, poor hair growth resulting in sparse hair, low posterior hairline, open anterior fontanelle, mild neck webbing, and pectus excavatum. She had a prominent philtrum, short nose, high palate, and thin upper lip. Her karyotype was $46, \mathrm{XX}$. A bone age of 1.8 years was recorded at 3 years. Intellectual development was mildly slow; she was the offspring of highly intelligent parents and she was just managing at normal school. A combined sensorineural and con-
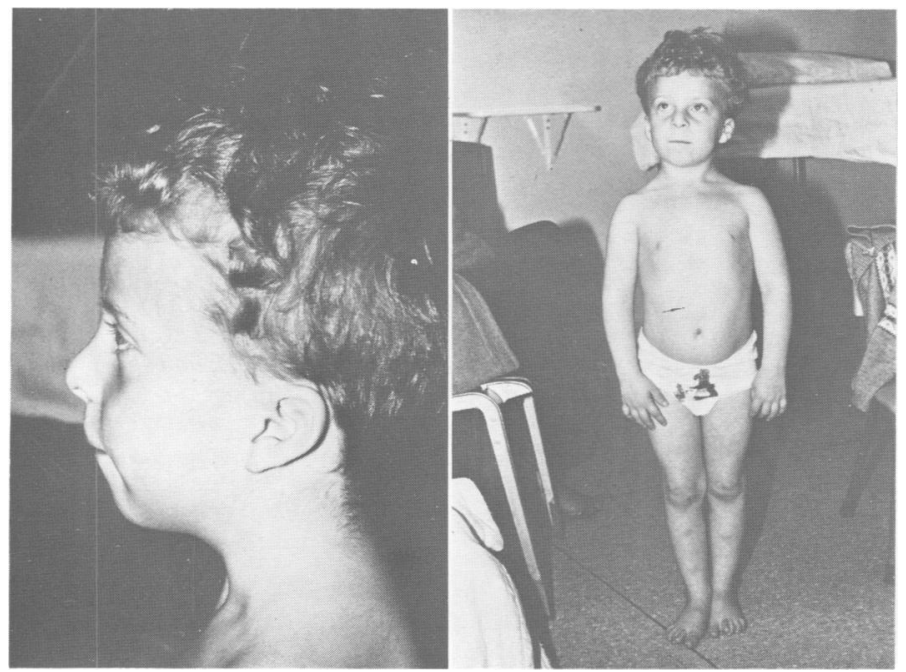

FIG 1 Photographs of case 1 aged 5 years. Note the short nose, mild webbing of neck, and posteriorly rotated ears. 
ductive deafness has recently been discovered. A heart murmur was heard over the pulmonary area but this subsequently disappeared. At 5 years her height is below the 3rd centile, her weight on the 10th, and her head circumference on the 50th.

\section{CASE 2 (FIG 2)}

This female was born by lower segment caesarian section. Her birth weight was $3 \cdot 3 \mathrm{~kg}$. Excessive skin was noted at birth especially in the neck and face and this was removed at the age of 2 years. The following features were noted at $61 / 2$ years of age. She was intellectually slow and attended a special school for the mentally handicapped. Her height was well below the 3 rd centile $(93.4 \mathrm{~cm})$. Her hair was blonde, low down on the neck, sparse, and had never been cut. Webbing of the neck was still evident despite surgery. She had a prominent philtrum, generous upper lip, a short nose with anteverted nostrils, prominent, large, posteriorly rotated ears, and sparse eyebrows. Examination of her chest revealed pectus excavatum, but her nipples were normally spaced. Her eyes were horizontal in position and hypertelorism, ptosis, or epicanthus were not present. She had limited extension of the elbows and short little fingers. There was a murmur of pulmonary stenosis, but her echocardiogram was normal. Her karyotype was $46, X X$.

\section{CASE 3 (FIG 3)}

This male was born at term with a birth weight of $2.47 \mathrm{~kg}$. The pregnancy was uneventful. The father was $167.7 \mathrm{~cm}$ tall and the mother was $164.5 \mathrm{~cm}$ tall. Soon after birth it was noted that the proband's head circumference was increasing and a moderate hydrocephalus was diagnosed and shunted. When seen at the age of 5 years his height was $85 \mathrm{~cm}$ (5 SD below the mean). He had an IQ of 89 but coped at an ordinary school.

On examination, he had low set, posteriorly rotated ears, a small nose ('snub nose'), and epicanthic folds. He had a squint but no hypertelorism. His nails grew poorly and his teeth were decayed. He sweated normally. His left testicle was undescended. Examination of the cardiovascular system was normal. A skeletal survey revealed some narrowing of the interpedicular distances between L1 to L5, but was otherwise normal. His bone age at 5 years was three years behind. His mother was a professional hairdresser and stated that her son's hair was extremely sparse and had only been cut once or twice in five years.

CASE 4 (FIG 4)

This female was born at 37 weeks weighing $3.6 \mathrm{~kg}$. She was in the special care nursery for 10 days because of poor feeding. At one month of age she was readmitted to the children's ward and found to have a hypertrophic cardiomyopathy. Her development has been delayed. She smiled at 8 weeks and sat up at 7 months. At 2 years she walks with assistance but not alone. She has said a few words but she does not show much interest in her surroundings and shows little evidence of cognitive development. She is probably functioning around the level of a 10 month old child. She is the oldest child of unrelated parents. There is a marked family history of deafness. Her father is deaf and this was thought to have occurred after a measles infection at

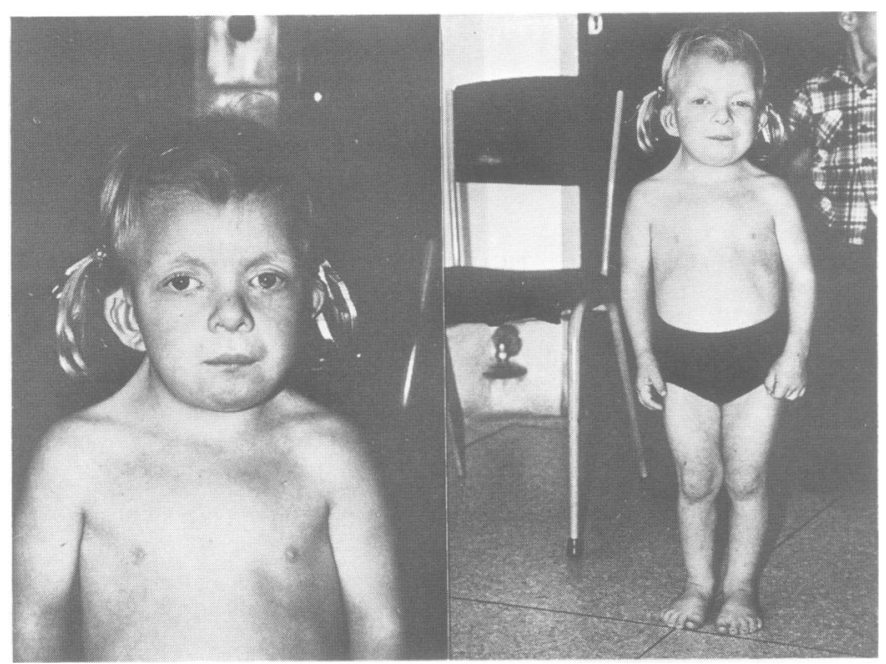

FIG 2 Photographs of case 2 aged 7 years. Note the webbed neck and short nose with broad nasal tip. 

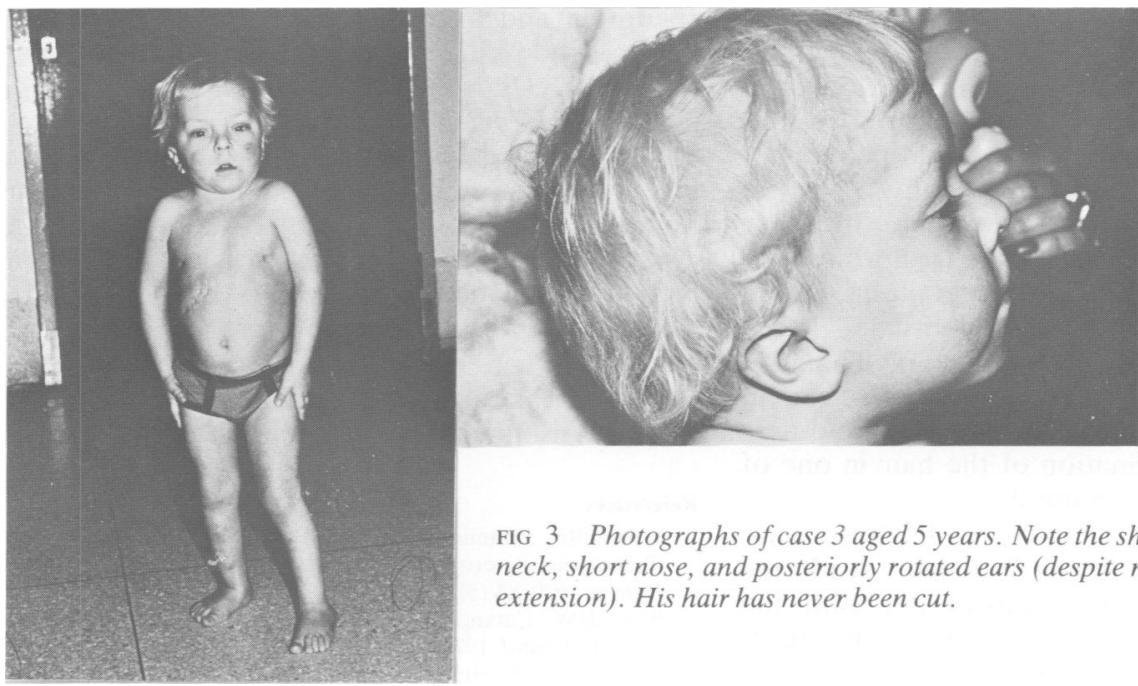

FIG 3 Photographs of case 3 aged 5 years. Note the short neck, short nose, and posteriorly rotated ears (despite neck extension). His hair has never been cut.
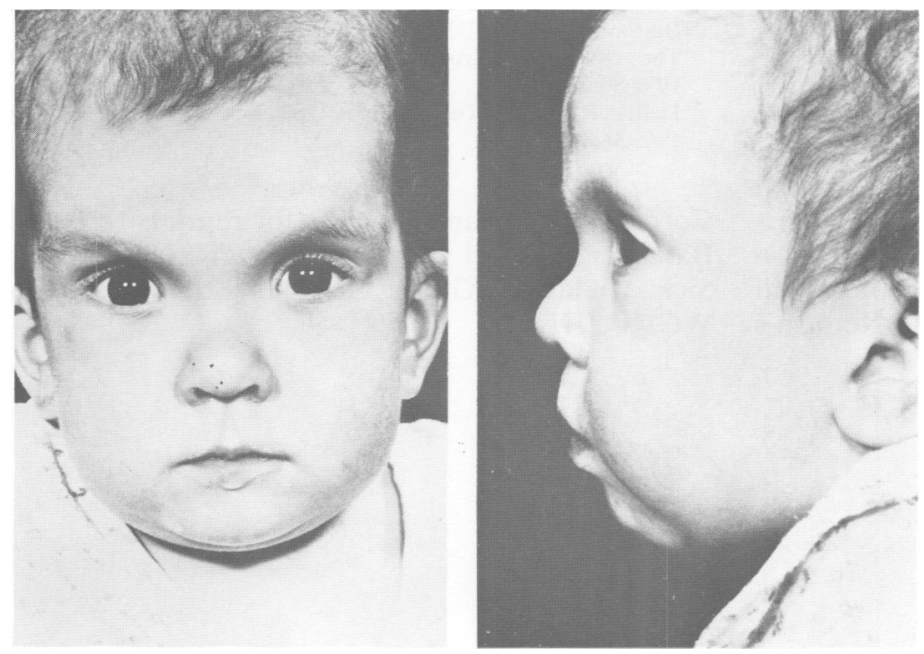

FIG 4 Photographs of case 4 aged 2 years. Note posteriorly rotated ears and sparse hair.

about 4 years of age. The mother's brother and both her parents were thought to be deaf from birth. There is also a strong family history of renal stones.

On examination, her head circumference was 47 $\mathrm{cm}$ (10th to 50th centile) and her length was $72 \mathrm{~cm}$ (<3rd centile). She had mild dysmorphic features. The interpupillary distance was $5.5 \mathrm{~cm}$ (75th to 97 th centile) and the inner canthal distance was $2.75 \mathrm{~cm}$ (75th centile). She had a broad flat nasal bridge and a short neck.

A number of investigations were carried out. A brain scan was performed and suggested the presence of brain stem atrophy. There were dilated third and lateral ventricles and also a wide sylvian fissure probably indicative of hypoplasia. Auditory evoked responses showed an absence of response with right ear stimulation suggesting that the auditory pathways to the right ear were affected. There was also a less severe abnormality on stimulation of the left side. It was noted that for a child of 2 years she had very poor hair growth and it had never been cut.

\section{Discussion}

All four children reported here had a significant lack of hair growth and cutting had seldom been needed. When the hair did grow it was not a luxuriant growth and parents commented that it was sparse. The 
other features common to all the children in this report are short stature, mildly slow development, posteriorly rotated ears, short nose, and low hairline. Pulmonary heart murmurs occurred in two (one of them was thought to have mild pulmonary stenosis and one had a cardiomyopathy).

Poor hair growth can be a feature in other dysmorphic syndromes. It occurs in trichorhinophalangeal syndrome, cartilage hair hypoplasia, incontinentia pigmenti, Coffin-Siris syndrome, hypomelanosis of Ito, progeria, Rothmund-Thomson syndrome, and Werner syndrome, but these can all be excluded as their dysmorphology is quite different. Histological examination of the hair in one of our cases (case 2) was normal.

There are two ways of interpreting these data. Firstly, these children all have Noonan's syndrome without the typical facial features but with the characteristic body habitus, webbing of the neck, cardiac pathology, and low IQ. Facially they had few of the dysmorphic features associated with Noonan's syndrome. Mild hypertelorism was only present in one, and none had an antimongoloid eye slant.

Hair abnormalities are recognised in Noonan's syndrome. ${ }^{2}$ Woolly or curly hair and a low trident hairline are commonly seen. There have been two reports of sparse eyebrows with follicular hyperkeratosis in the interciliary area. ${ }^{3}{ }^{4}$ There have also been reports of poor beard growth and poor growth of axillary and pubic hair in patients with Noonan's syndrome and a normal chromosome karyotype. ${ }^{5}$ To our knowledge there has not been a previous report suggesting that sparse growth of scalp hair is a feature of Noonan's syndrome.

The second possibility, and the one which we favour, is that the phenotype illustrated in this report of short stature, sparse hair growth, posteriorly rotated ears, trident hairline, and mild mental retardation represents a distinctive, previously unreported syndrome.

We would like to thank Drs M Preece, M Savage, and $\mathrm{J}$ Wilson for referring the patients.

\section{References}

I Wilroy RS, Summitt RL, Tipton RE, Primm PA, Martens PR. Phenotypic heterogeneity in the Noonan syndrome. Birth Defects 1979;XV(5B):305-11.

2 Wyre HW. Cutaneous manifestations of Noonan's syndrome. Arch Dermatol 1978;114:929-30.

3 Pierini DO, Pierini AM. Keratosis pilaris atrophicans faciei (ulerythema ophryogenes): a cutaneous marker in the Noonan syndrome. Br J Dermatol 1979;100:409-16.

4 Bolton MR, Pugh DM, Mattoli LF, Dunn MI, Schamke RN. The Noonan syndrome: a family study. Ann Intern Med 1974;80:626-9.

5 Heller RU. The Turner phenotype in the male. $J$ Pediatr 1965;66:48-63.

Correspondence and requests for reprints to Dr $\mathrm{M}$ Baraitser, Clinical Genetics Unit, The Hospital for Sick Children, Great Ormond Street, London WC1N $3 \mathrm{JH}$. 